\title{
Assessment system of condition of typical building infrastructure using fuzzy analitical hierarchy procces (FAHP) method
}

\author{
Firman Javiri ${ }^{1, *}$, Akhmad Aminullah ${ }^{1}$, and Andreas Triwiyono ${ }^{1}$ \\ ${ }^{1}$ Department of Civil and Environmental Engineering, Gadjah Mada University, Yogyakarta, Indonesia
}

\begin{abstract}
Conditions existing infrastructure needs to be maintained, it can be operated / function, so we need a good maintenance. Operation and maintenance activities carried out in a sustainable manner, to restore, optimize, and service live function according to design life. Assessment of the condition is a link between opration and maintenance functions. If the conditions are bad, then the operation will not be optimal, which could result in malfunction. In this research, case studies assess the conditions of student dormitory buildings with prototype design. Weighting component using Fuzzy Analytical Hierarchy Process as a method of analysis. The results of the analysis show that by using the FAHP method, the weighting of building components from the assessment of the subjectivity of expert respondents can be calculated. The result of this weighting Component can be used as a calculation factor of the value of the condition of the building, and can be applied to student dormitory buildings with typical design.
\end{abstract}

\section{Introduction}

\subsection{Background}

Simple Flats Rent (Rusunawa) is a simple apartment rented to urban communities who cannot afford to buy a house or want to stay for a while such as students, temporary workers and others. Vertical housing or tenement is a solution for handling of housing complex and settlement slums and prevent growing slums new as a consequence of a speedy development urban area that had impact on the growing population density, the building density, poor quality of infrastructure and the scarcity of land reserved for settlement. Construction of rusunawa made by the government to university can be called student dormitory that have been implemented in every provincial government in Indonesia since 2003.

The University of Gajah Mada as one of universities exacted in the city of yogyakarta to the total number of students more or less 8745 a new student every year has prepared the needs of temporary shelter with build student dormitories. Currently there are six student dormitories with twin block designs that have been operating, therefore the condition of existing infrastructure needs to be maintained, in order to keep it operational / functioning, so it needs good maintenance. Operation and maintenance activities are carried out sustainable, to restore, optimize, and even improve the service function in accordance with the age of the plan. Assessment of conditions is the link between the operational and maintenance functions. If conditions are bad, then operational will not be optimize which could result in the failure of function [1]. In order to manage the operation and maintenance of this can take place required a system of assessment of the condition of the building infrastructure. In Indonesia, the management system that regulates information on building infrastructure data is still not implemented. Therefore, the information support system of the assessment of a building must be developed because as monitoring the condition and basis of decision making for the handling of operational and maintenance of building.

\subsection{Research Objectives}

Based on the background research, it can be formulated problem that will be the object of this research that is, How to create a weighting system and priority scale using Fuzzy Analytical Hierarchy Process method. The purpose of this study are establish a building assessment system using the weighted method of each major component and supporting the building nd provide an alternative support in determining decisions for the maintenance of buildings that can be applied to similar buildings / typical. This method is expected to be a method and system of assessment of alternative building condition alternative as

\footnotetext{
* Corresponding author: firmanjaviri@gmail.com
} 
supporting decision making handling operation and maintenance of infrastructure for manager.

\section{Literature Review}

[2] With the use of fuzzy analytic hierarchical process (FAHP) and fuzzy transformation matrix (FTM), this research takes the policies related to intelligent green building promoted in Taiwan during 1999-2015 as subjects, so as to extract the collective intelligence of senior domain experts to evaluate the contribution weight ranking of each policy measures to achieve policy goals; in addition, with the implementation of policy measures of green building label, intelligent building label and green building material label in each year during this period, the growth and decline in evaluation cases are analyzed to testify the feasibility of policy evaluation method proposed. The results show that: 1.Use of FAHP and FTM to extract the collective intelligence from senior experts can establish policy evaluation method with reference value; 2 . The additional building bulk incentive for private building, mandatory control for public building, mandatory incorporation of green public purchase into green building material are the most effective policy measures in Taiwan; 3.Implementation of control measures in the stage of design and planning for new buildings is superior to the control in the stage of operation and management in effectiveness.

[3] The impact of buildings on the environment has created the need for green or sustainable buildings, which aim to reduce energy and resource consumption. Sustainable building assessment methods have emerged in recent years as a means to evaluate the performance of buildings across a broad range of sustainability considerations. This research presents a conceptual model for the assessment of sustainable commercial buildings with the use of fuzzy logic and the analytic hierarchy process (AHP). It covers 100 sustainability criteria. The proposed building evaluation model depends on two types of parameters: endogenous (constants: global weights of criteria) and exogenous (variables: performance score of building for each criterion). A building's sustainability score reflects the interplay between these two parameters. Global weights of criteria can be developed through AHP. The performance scores of criteria can be determined through fuzzy logic. The proposed approach of building evaluation can produce significant benefits that are not likely to result from conventional practices.

[4] Maintenance of piers structures in harbor was absolut ely required to be taken by the management in order to ensure and facilitate ships' activities. It is used in order to keep the structures in good condition during their planned service life. The objective of this study is to construct a structure evaluation method or system, which is for piers structures, by obtaining each score of the piers structure component and providing alternatives for allocated maintenance fund that gives priority based on the component score. The score was obtained by using the Analytical Hierarchy Process (AHP) as a supporting method. The AHP method was used for obtaining score for the 2nd level criteria, such as the structural, functional, architectural, and cost; as well as for the piers structure components, such as pile, apron pavement, fender, bollard, pile, printed concrete, bulkhead, and catodic protection. The results of the scoring shown: (formula)Y Piers Structure $=0,554 . \mathrm{STR}+0,248 . \mathrm{FGS}+0,126 . \mathrm{ARS}+$ 0,073.BIA(formula) (formula)Y Piers Structures = $0,197 \cdot \mathrm{TP}+0,169 \cdot \mathrm{PA}+0,147 . \mathrm{FD}+0,137 . \mathrm{BL}+0,139 . \mathrm{TB}$ $+0,059 \cdot \mathrm{BC}+0,092 \cdot \mathrm{TR}+0,059 \cdot \mathrm{KP}$ (formula) After these results were applied and tested to the piers structure, the followings showed the resulted scores: a. Dermaga Samudera for Tanjung Emas Harbor in Semarang showed an index of 6.585 (given by the researcher) and 6.554 (score based on the questionnaire). These figures showed that the piers structure was considered in "fair" chategory. b. Dermaga Terminal Peti Kemas in Semarang showed an index of 7.328 (score given by the researcher) and 7.544 (score based on the questionnaire). These figures indicated that the piers structure was categorized as "fair". c. Piers Structure in Sampit Harbor showed an index of 7.491 (score given by the researcher) and 7.50 (score based on questionnaire). These features showed that the piers structure was categorized as "fair".

\section{Metodology}

\subsection{Type of Building Damage}

According to the Minister of Public Works and Housing Regulation No.24/2008 on Guidelines for Maintenance of Buildings, the maintenance of buildings is an activity to maintain the reliability of the buildings and infrastructure and facilities so that the building is always functional. In order for maintenance management to take place required a system of assessment of the condition of the building infrastructure with a scope consisting of Architectural, Structural, Mechanical, Electrical, Outdoor Spatial, and Housekeeping. [5]

The damage buildings is defined as the nonfunctioning of buildings or building components due to depreciation / end of life of the building, or the result of human activities or natural behavior such as excessive function load, fire, earthquake, other like. The intensity of damage to buildings can be classified on three levels of damage, as follows:

1 Minor damage

Minor damage is especially damage to non-structural components, such as roof coverings, ceilings, floor coverings, and filler walls. Treatment for minor damage rates, the maximum cost is $35 \%$ of the highest unit price of new building construction applicable, for the same type / class and location.

2 Medium damage

Medium damage is damage to some non-structural components, and / or structural components such as roof structures, floors, and others. Treatment for moderate damage rates, the maximum cost is $45 \%$ of the highest unit price of newly constructed building construction, for the same type / class and location.

3 Severely damage

Severely damage is damage to most building components, both structural and non-structural which, 
when repaired, can still function properly as appropriate. The maximum cost is equal to $65 \%$ of the highest unit price of newly applicable building construction, for the same type / class and location.

The Condition Index (CI) has a scale of 0 (zero) to 100 (one hundred), the condition index is 0 (zero) means the building is not working and 100 (one hundred) means the building is still in excellent condition. One condition index is a scale developed [6], as in table 1 .

[7] five defects categories were classified under these categories. These categories include location, materials, defect descrip-tion, failure mechanisms, elements, design parameters, and roots.

Based on literature review grouping damage categories modified and adapted to the conditions of student dormitory building elements. for example grouping the type of damage to the wall elements shown in table 2 .

Table 1. Scale of building condition index (McKay et al., 1999)

\begin{tabular}{|l|l|}
\hline Condition Index & Description of Conditions \\
\hline $85-100$ & $\begin{array}{l}\text { Very good: no visible damage, some } \\
\text { flaws may be visible }\end{array}$ \\
\hline $70-84$ & $\begin{array}{l}\text { Good: minor deterioration damage, } \\
\text { there was a small real damage }\end{array}$ \\
\hline $55-69$ & $\begin{array}{l}\text { Medium: Starts deterioration of } \\
\text { damage but does not affect the overall } \\
\text { structure of the building }\end{array}$ \\
\hline $25-54$ & $\begin{array}{l}\text { Quite: there is deterioration or damage } \\
\text { but the building is still quite } \\
\text { functioning }\end{array}$ \\
\hline $10-24$ & $\begin{array}{l}\text { Poor: critical damage occurs so the } \\
\text { building function is disrupted }\end{array}$ \\
\hline $0-9$ & $\begin{array}{l}\text { Very Poor: severe damage and the } \\
\text { building barely works }\end{array}$ \\
\hline
\end{tabular}

Table 2. Summary of Defeect Wall Element (Chong and Low , 2006)

\begin{tabular}{|l|l|l|}
\hline No & Defect Conditions & Discription \\
\hline 1 & Plaster crack & \\
\hline 2 & Water seepage & \\
\hline 3 & Stain & \\
\hline 4 & $\begin{array}{l}\text { Paint peeling and blister } \\
\text { Paint }\end{array}$ & \\
\hline 5 & Paint and plaster patchy & \\
\hline 6 & Chipped & \\
\hline
\end{tabular}

\subsection{Weighting of building components}

Calculation of elemental weights begins with the hierarchy of elements, components and sub-components. This weighting is required to calculate the condition index of the building. Based on literature review, weighted hierarchy adjusted to physical category of student dormitory building using Fuzzy Analytic Hierarchy Process (FAHP) method with description as Table 3.

Table 3. Hierarchy of weighting element building

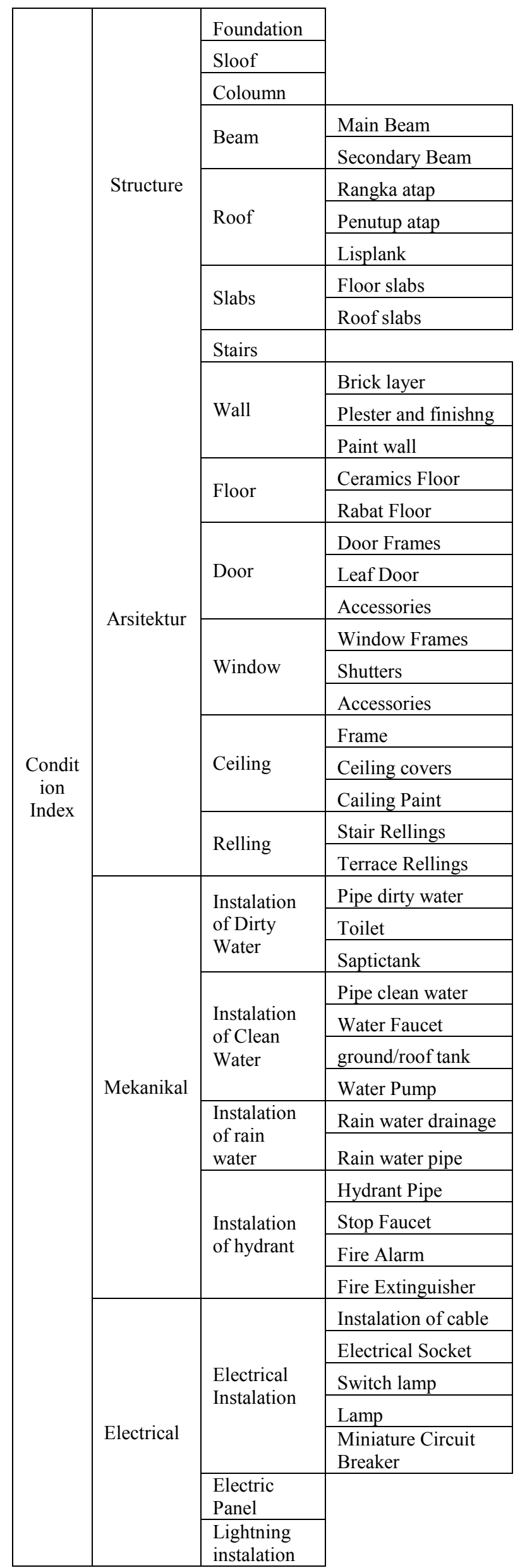




\subsection{Anaytical Hierarchy Process (AHP)}

Analytic Hierarchy Process (AHP) is one of the special methods of Multi Criteria Decision Making (MCDM) introduced [8] . AHP is useful as a tool in decision analysis and has been widely used in many fields.

AHP is perfect for complex decisions that involve comparison of decision elements that are difficult to measure. It is based on the assumption that when confronted with complex decisions human natural reactions are to classify the elements of decisions according to their general characteristics. This is a decision-making technique where there are a number of options, but where each has a number of different criteria, some or all of which may be difficult to formalize. When will make a comparison decision between each pair in each cluster (as a matrix). Further weight will be given for each element in a cluster (or hierarchical level) and a consistency ratio $(\mathrm{CR})$ is useful for checking data consistency [9].

[10] States that solving the problem with the AHP method, there are several basic principles that must be understood. Decision hierarchy is called complete if all elements at a level have a relationship to all elements present at the next level on Figure1. While in the hierarchy of incomplete decisions not all elements at each level have a relationship.

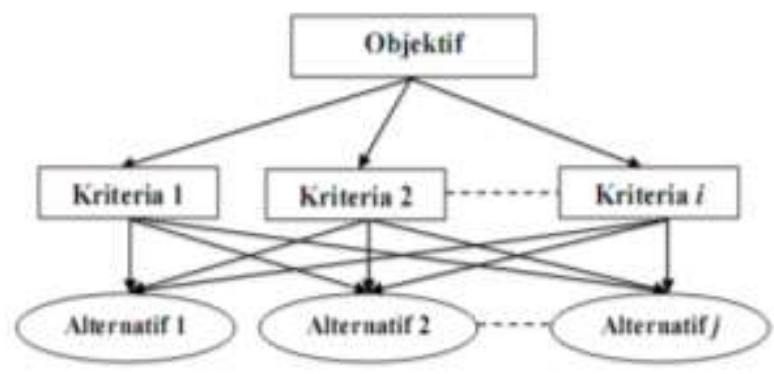

Fig.1. AHP Hierarchy Structure (Saaty \& Vergas 2012)

\subsubsection{Set priorities}

[11] Tutorials to define the elements in a decision problem by making pairwise comparison, ie the elements are compared in pairs against one specified criterion. This pairwise comparison is presented in matrix form. The scale to fill this matrix is 1 to 9 (Saaty scale) with explanation in the table 4 .

Table 4. Scale for pairwise comparison (Saaty, 2012)

\begin{tabular}{|c|l|}
\hline $\begin{array}{l}\text { Intensity of } \\
\text { Interest }\end{array}$ & Discription \\
\hline 1 & Equally important \\
\hline 3 & Moderately importance \\
\hline 5 & Strongly importance \\
\hline 7 & Very strongly important \\
\hline 9 & Extremely more important \\
\hline $2,4,6,8$ & Values between two adjacent considerations \\
\hline
\end{tabular}

\begin{tabular}{|c|l|}
\hline $1 /(1-9)$ & $\begin{array}{l}\text { The reverse value of the importance level of } \\
\text { the scale 1-9 }\end{array}$ \\
\hline
\end{tabular}

With :

w $\mathrm{i}=$ bobt element $\mathrm{i}, \mathrm{i}=1, \ldots . ., \mathrm{n}$

where $\mathrm{n}=$ many elements

a $\mathrm{ij}=$ wi / wj = pairwise comparison result between element $\mathrm{i}$ compared with element $\mathrm{j}$

$\mathrm{A}=$ matrix of aij comparison values

A paired set can be represented as table 5 .

Table 5. Pairwise Comparison Matrix

\begin{tabular}{|c|c|c|c|c|}
\hline & A1 & A2 & $\ldots$ & An \\
\hline A1 & $\begin{array}{c}\text { W1/ } \\
\text { W1 }\end{array}$ & $\begin{array}{c}\text { W1 } / \\
\text { W2 }\end{array}$ & $\cdots$ & $\begin{array}{c}\text { W1/ } \\
\text { Wn }\end{array}$ \\
\hline A2 & $\begin{array}{c}\text { W2/ } \\
\text { W1 }\end{array}$ & $\begin{array}{c}\text { W2/ } \\
\text { W2 }\end{array}$ & $\cdots$ & $\begin{array}{c}\text { W2/ } \\
\text { Wn }\end{array}$ \\
\hline$\vdots$ & $\vdots$ & $\vdots$ & & $\vdots$ \\
\hline An & Wn/ & Wn $/$ & $\ldots$ & $\begin{array}{c}\text { Wn } / \\
\text { Wn }\end{array}$ \\
\hline
\end{tabular}

Where $\mathrm{W} 1$ / W2 is a value that reflects the interest value of element A1 compared to element A2. because the actual result of the pairwise ratio is 'A ij', where 'a 12' equals W1 / W2, the matrix A becomes table 6 .

Table 6. Matrix of Interest Option Intensity Comparison

\begin{tabular}{|c|c|c|c|c|}
\hline & A1 & A2 & $\ldots$ & An \\
\hline A1 & 1 & $a 12$ & $\cdots$ & $a 1 n$ \\
\hline A2 & $a 21$ & 1 & $\cdots$ & $a 2 n$ \\
\hline$\vdots$ & $\vdots$ & $\vdots$ & $\cdots$ & $\vdots$ \\
\hline An & $a n 1$ & $A n 2$ & $\cdots$ & 1 \\
\hline
\end{tabular}

\subsubsection{Consistency}

In pairwise comparison appraisal there is often an inconsistency of opinions / preferences given by the decision maker. The consistency of the paired assessment is evaluated using the Consistency Ratio (CR). Whenever set if $\mathrm{CR} \leq 0.1$, then the result of the assessment is said to be consistent. The formula for calculating $\mathrm{CR}$ is equation 1 and 2 .

$$
\begin{aligned}
& C R=\frac{C I}{R I} \\
& C I=\frac{\lambda_{\text {max }}-n}{(n-1)}
\end{aligned}
$$

Where $\lambda \max =$ maximum value of eigen value of order $n$. The maximum value of Eigen is obtained by summing the matrix comparison product with the main eigen vector (priority vector) and dividing by the number of elements. The value of CI will be meaningless if there is no reference to indicate whether CI indicates a consistent or inconsistent matrix. Saaty get the average value of random Index (RI) as in the table7. 
The range $\mathrm{CR}=$ Consistency Ratio may vary according to the matrix size of 0.05 to $3 \times 3$ matrices, 0.08 to $4 \times 4$ matrices, and 0.1 for all matrices greater than $\mathrm{n} \geq 5$. If the CR value is equal, or less than that value $(0.1)$, indicates that the evaluation in the matrix is received or indicates a consistency level well in comparison to the matrix.
Conversely, if CR is more than an acceptable value (0.1) then inconsistency has occurred in the matrix and therefore the evaluation process should be reviewed and corrected. Acceptance of $\mathrm{CR}$ will help to ensure the reliability of the decision maker in determining the priority of a number of criteria.

Table 7. Random Index Value

\begin{tabular}{|c|c|c|c|c|c|c|c|c|c|c|c|c|c|c|c|}
\hline Ordo Matrix & 1 & 2 & 3 & 4 & 5 & 6 & 7 & 8 & 9 & 10 & 11 & 12 & 13 & 14 & 15 \\
\hline RI & 0 & 0 & 0,85 & 0,9 & 1,12 & 1,24 & 1,32 & 1,41 & 1,45 & 1,49 & 1,51 & 1,48 & 1,56 & 1,57 & 1,59 \\
\hline
\end{tabular}

One reason for $\mathrm{CR}$ calculations is that the human element (decision maker) cannot always be absolutely consistent in expressing the preferences of the comparable elements. In other words, that the judgments given for each element of the problem at a hierarchical level may be inconsistent.

\subsection{Fuzzy Anaytical Hierarchy Process (FAHP)}

Basically the steps in the FAHP method are almost identical to the AHP method in Multi Criteria Decision Making (MCDM) by Saaty used for decision applications with a judgment scale of 1-9. In this study the judgment to provide value in pairwise comparisons, many containing uncertainty factors such as the assessment between the sub criteria of the floor component with the door / window, the decision maker would have difficulty in determining the right scale value of interest between the two because there is no fixed value that the floor component (for example) worth 7 (more important) than the door / window components.

To solve the problem, this research is proposed by using fuzzy set theory to represent uncertainty of one's judgment to number. Unlike in the conventional AHP method using a predefined standard scale, ie 1-9 in pairwise comparison, the FAHP is replaced by a fuzzy number and linguistic variables in comparing the two criteria, sub criteria, or alternatively. In other words FAHP is an analytical method developed from the AHP method.

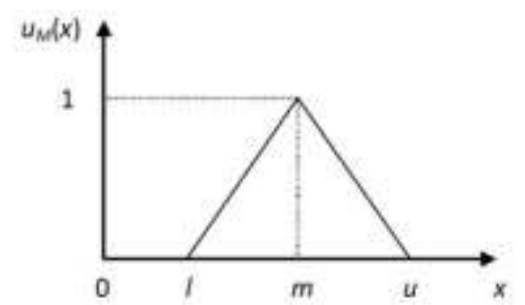

Fig.2. Triangular Fuzzy Number (TFN) (Saaty \& Vergas 2012)

In this research, FAHP method applied is Triangular Fuzzy Number (TFN) or fuzzy triangle number for fuzzyfication process from crisp comparison matrix. Blurred data will be presented in TFN (figure 2). TFN is a special class of fuzzy numbers whose each membership function is defined in 3 real numbers, that is, $(1, m$, and $\mathrm{u}$ ), where 1 is the lowest possible value, $m$ is the value of the possibility of the middle / peak value entered by the user or the most probably from one fuzzy number, and $u$ is the highest possible value at the decision maker's decision interval. The values of $1, \mathrm{~m}$, and $\mathrm{u}$ can also be determined by the decision maker itself. The following three fuzzy blangan parameters are proposed for representing the Saaty scale (1-9) according to their importance:

$1 \equiv(1,1,2)$
$\mathrm{x} \equiv(\mathrm{x}-1, \mathrm{x}, \mathrm{x}+1) ; \mathrm{x}=2,3 \ldots 9$
$9 \equiv(9,9,9)$

For the AHP scale is changed to TFN, scale 1 becomes $(1,1,2)$, scale 9 becomes $(9,9,9)$ and other scale is $2,3,5$, for example $\mathrm{x}=3$ with the above equation becomes $(2,3$, 4). Obtained from 3-1, 2 obtained and 4 obtained from 3 +1 . Unless pairwise comparisons on diagonal values are always $(1,1,1)$.

With Triangular Fuzzy Number (TFN) can minimize pairwise comparison uncertainty or can indicate the exact degree of uncertainty. In this case linguistic variables can be used by decision makers to present data uncertainty in case of any inconvenience. Chang introduced a new approach based on this TFN number to handle the pairwise comparison scale followed by the use of analytical methods to what extent the synthetic limit values of pairwise comparisons. The following is a TFN scale membership function in the linguistic variable in Table 8 and Figure 3 used in this study to provide a pairwise comparison value [12].

Table 8. TFN scale membership functions and linguistic variables

\begin{tabular}{|l|c|c|}
\hline \multicolumn{1}{|c|}{ Definition } & $\begin{array}{c}\text { AHP } \\
\text { Scale }\end{array}$ & $\begin{array}{c}\text { FAHP } \\
\text { Scale }\end{array}$ \\
\hline $\begin{array}{l}\text { Equally important, besides the } \\
\text { diagonal }\end{array}$ & 1 & $(1,1,2)$ \\
\hline Almost important enough & 2 & $(1,2,3)$ \\
\hline Quite important & 3 & $(2,3,4)$ \\
\hline Almost more important & 4 & $(3,4,5)$ \\
\hline More important & 5 & $(4,5,6)$ \\
\hline
\end{tabular}

If pairwise comparisons do not meet the above scale but are the opposite values, then the inversion is used as in the following table 9.

Table 9. TFN-scale membership functions and linguistic variables

\begin{tabular}{|l|c|c|}
\hline \multicolumn{1}{|c|}{ Definition } & $\begin{array}{c}\text { AHP } \\
\text { Scale }\end{array}$ & FAHP Scale \\
\hline Almost not important enough & $1 / 2$ & $(1 / 3,1 / 2,1)$ \\
\hline Quite unimportant & $1 / 3$ & $(1 / 4,1 / 3,1 / 2)$ \\
\hline Almost less important & $1 / 4$ & $(1 / 5,1 / 4,1 / 3)$ \\
\hline More unimportant & $1 / 5$ & $(1 / 6,1 / 5,1 / 4)$ \\
\hline
\end{tabular}




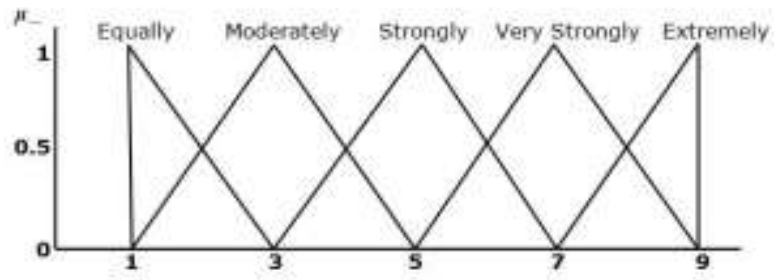

Fig.3 TFN-scale membership functions and linguistic variables

[13] The analysis of fuzzy synthetic extents ( $\mathrm{Si}$ ) is used to obtain the expansion of an object in achieving a goal called statisfied extant. If $\mathrm{g}=[\mathrm{g} 1, \mathrm{~g} 2 \ldots . \mathrm{gn}]$ is a set of criteria of $n$, and $A$ is an alternative set of $m$, then for fuzzy M equation 3.

$$
M_{g i}^{1}, M_{g i}^{2}, \ldots \ldots . . . M_{g i}^{m}
$$

$\mathrm{M}$ is the extant value of the i-criteria and m-alternative decision where $\mathrm{i}=1,2, \ldots ., \mathrm{n}$ and for all, is a fuzzy triangular number.equation 4.

$$
M_{g i}^{J}(J=1,2, \ldots \ldots, M)
$$

(4)

The steps of completion of fuzzy AHP according to are as follows:

1. Create a hierarchical structure of the problem to be solved and determine the ratio of matrix in pairs between criteria with TFN scale at each value is calculated geometric mean.

2. Defining the value of fuzzy synthetic extent $(\mathrm{Si})$ with the criterion $i$ is defined as the following equation 5 .

$$
S i=\sum_{j=1}^{m}{ }_{g i}^{J} x\left[\sum_{i=1}^{n} \sum_{j=1}^{n}{ }_{g i}^{J}\right]^{-1}
$$

To obtain the equation 6 .

$$
\sum_{j=1}^{m} M_{g i}^{J}
$$

a fuzzy sum operation is performed from the value of $\mathrm{m}$ at equation 7 .

$$
\sum_{j=1}^{m} M_{g i}^{J}=\left(\sum_{j=1}^{m} l j, \sum_{j=1}^{m} m j, \Sigma_{j=1}^{m} u j\right)
$$

Matrix in the equation below. In the final calculation phase, values $(1, \mathrm{~m}, \mathrm{u})$ are obtained and used for the next step. Where 1 is the lower limit value, $m$ is the expected value and $\mathrm{u}$ is limiting the upper value. To get the equation 8 .

$$
\left[\Sigma_{j=1}^{n} \Sigma_{j=1}^{m} M_{g i}^{J}\right]^{-1}
$$

A fuzzy sum operation is performed from the value of $\operatorname{gij}(\mathrm{J}=1,2, \ldots \ldots . . \mathrm{m})$ to obtain the following equation 9.

$$
\sum_{i=1}^{n} \sum_{j=1}^{m} M_{g i}^{J}=\left(\sum_{i=1}^{n} l i, \sum_{i=1}^{n} m i, \sum_{i=1}^{n} u i\right)
$$

Then calculate the inverse of the vector in the above equation so that we get the equation 10 .

$$
\left[\sum_{j=1}^{n} \sum_{j=1}^{m} \underset{g i}{M}\right]^{-1}=\frac{1}{\sum_{i=1}^{n} u i}, \frac{1}{\sum_{i=1}^{n} m i}, \frac{1}{\sum_{i=1}^{n} l i}
$$

3. Calculating the degree of possibility

To obtain the degree of possibility, M2 $=(12, \mathrm{~m} 2, \mathrm{u} 2)$ $\geq \mathrm{M} 1=(11, \mathrm{~m} 1, \mathrm{u} 1)$ is expressed in the equation 11 . $V\left(M_{2}>M 1\right)=\sup [\min (\mu m i(x), \mu m i(y))]$
And $x$ and $y$ are the values on the axis of the membership function of each criterion. This equation can be defined as fig 4 .

$$
\mathrm{V}\left(\mathrm{M}_{3} \geq \mathrm{M}_{1}\right)=\left\{\begin{array}{ccc}
1 & \text { if } & m_{2} \geq m_{l} \\
0 & \text { if } & l_{2} \geq x_{2} \\
\frac{l_{1}-\mathrm{ul}_{2}}{\left(m_{2}-l_{2}\right)-\left(m_{l}-l_{l}\right)} & \text { Otherwise }
\end{array}\right.
$$

Fig.4 Matrix of the membership function of each criterion Comparing M1 and M2 we need values of equation 12.

$$
V=\left(M_{2} \geq M_{1}\right), \text { and } V=\left(M_{1} \geq M_{2}\right)
$$

4. Comparing degree of possibility between criteria Comparison between degrees of possibility between $M i(i=1,2,3,4,5 \ldots k)$ can be defined

By equation 13 .

$V=\left(M \geq M_{1}, M_{2}, M_{3} \ldots M_{k}\right)=V\left[\left(M \geq M_{1}\right),\left(M \geq M_{2}\right) \ldots\left(M>M_{K}\right)\right]$ and $, V=\left(M>M_{i}\right),(i=1,2,3 \ldots k)$

Assumed in the equation 14.

$d^{\prime}(A i)=\min V(S i \geq S k)$ for $k=1,2,3,4,5, \ldots . ., n ; k \neq i$.

Then the weight vector is given by the equation as equation 15 .

$W^{\prime}=\left(\left(d\left(A_{1}\right),\left(d\left(A_{2}\right), \ldots \ldots \ldots . ., d\left(A_{n}\right)\right)^{T}\right.\right.$

Where $A i(i=1,2,3,4,5, \ldots \ldots, n)$ is n elements.

5. Normalization

Normalization of vector weights is given in the equation 16.

$$
W=\left(\left(d\left(A_{1}\right),\left(d\left(A_{2}\right), \ldots \ldots \ldots ., d\left(A_{n}\right)\right)^{T}\right.\right.
$$

Where $\mathrm{W}$ is a non-fuzzy number which is the weight of the vector.

6. Calculates the global weight

After obtained the result of weighting of criterion vector and sub criterion then calculated global weight that is by multiplication of weight of criterion with sub criterion weight.

\section{Discutions}

\subsection{Case Study}

In this study the location of a typical building student dormitory in the University of Gajah Mada is located in Sleman Province Yogyakarta Province Indonesia.

\subsection{AHP fuzzy weighted analysis}

Primary data is a visual observation of the field and look for weighting criteria and sub-criteria through respondents by questionnaire method. Qualification of respondents based on the subjectivity of experts in their field with a total of 20 respondents are:

a) Minister of Public Works and Housing

b) Academics of Civil Engineering

c) Consultant Planner 
d) Consultant Supervisor

e) Contractor

Here is an example of respondent questionnaires on weighting criteria by appraising interests according to their subjectivity as in table 10 .

After determining the hierarchy structure then form a pairwise comparison matrix of geometric results of recapitulation of respondent data as in Table 11.

Table 10. Recapitulation of Respondent Data

\begin{tabular}{|l|l|l|l|l|l|l|}
\hline \multirow{2}{*}{ Responden } & Str & Str & Str & Ars & Ars & Mek \\
\cline { 2 - 7 } & Ars & Mek & Elk & Mek & Elk & Elk \\
\hline 1 & 5,00 & 5,00 & 5,00 & 3,00 & 3,00 & 1,00 \\
\hline 2 & 3,00 & 3,00 & 3,00 & 0,20 & 5,00 & 0,20 \\
\hline 3 & 5,00 & 7,00 & 7,00 & 0,14 & 3,00 & 1,00 \\
\hline 4 & 1,00 & 7,00 & 7,00 & 1,00 & 3,00 & 0,33 \\
\hline 5 & 7,00 & 1,00 & 1,00 & 0,20 & 5,00 & 3,00 \\
\hline$\vdots$ & $\vdots$ & $\vdots$ & $\vdots$ & $\vdots$ & $\vdots$ & $\vdots$ \\
\hline 15 & 5,00 & 1,00 & 5,00 & 0,33 & 3,00 & 0,33 \\
\hline 16 & 1,00 & 5,00 & 1,00 & 1,00 & 5,00 & 0,33 \\
\hline
\end{tabular}

\begin{tabular}{|l|l|l|l|l|l|l|}
\hline 17 & 7,00 & 3,00 & 3,00 & 3,00 & 1,00 & 1,00 \\
\hline 18 & 3,00 & 5,00 & 3,00 & 3,00 & 0,20 & 1,00 \\
\hline 19 & 3,00 & 3,00 & 1,00 & 5,00 & 1,00 & 3,00 \\
\hline 20 & 1,00 & 7,00 & 3,00 & 3,00 & 0,33 & 1,00 \\
\hline Geomean & 2,94 & 3,73 & 3,12 & 1,19 & 1,55 & 0,97 \\
\hline
\end{tabular}

Table 11. Comparative Matrix AHP scale criteria

\begin{tabular}{|l|l|l|l|l|}
\hline & Struktur & Arsitektur & Mekanikal & Elektrikal \\
\hline Structure & 1,00 & 2,94 & 3,73 & 3,12 \\
\hline Arsitektur & 0,34 & 1,00 & 1,19 & 1,55 \\
\hline Mekanikal & 0,27 & 0,84 & 1,00 & 0,98 \\
\hline Elektrikal & 0,32 & 0,65 & 1,03 & 1,00 \\
\hline
\end{tabular}

Pairwise comparison matrix of geometric AHP to calculate consistency ratio $(\mathrm{CR})$. Whenever accepted if $\mathrm{CR} \leq 0.1$

After that convert AHP value to FAHP and calculated geometric mean. Make pairwise comparison matrix shown in table 12 .

Table 12. Matrix Comparison of FAHP scale

\begin{tabular}{|c|c|c|c|c|c|c|c|c|c|c|c|c|}
\hline & \multicolumn{2}{|c|}{ Struktur } & \multicolumn{4}{|c|}{ Arsitektur } & \multicolumn{2}{|c|}{ Mekanikal } & \multicolumn{4}{|c|}{ Elektrikal } \\
\hline & $\mathrm{L}$ & M & U & L & M & U & $\mathrm{L}$ & M & U & $\mathrm{L}$ & M & U \\
\hline Struktur & 1,00 & 1,00 & 1,00 & 2,36 & 2,94 & 4,13 & 2,98 & 3,73 & 4,91 & 2,54 & 3,12 & 4,34 \\
\hline Arsitektur & 0,24 & 0,34 & 0,42 & 1,00 & 1,00 & 1,00 & 1,22 & 1,55 & 2,25 & 1,22 & 1,55 & 2,25 \\
\hline Mekanikal & 0,20 & 0,27 & 0,34 & 0,45 & 0,65 & 0,82 & 1,00 & 1,00 & 1,00 & 0,84 & 0,97 & 1,60 \\
\hline Elektrikal & 0,23 & 0,32 & 0,39 & 0,45 & 0,65 & 0,82 & 0,62 & 1,03 & 1,20 & 1,00 & 1,00 & 1,00 \\
\hline
\end{tabular}

After determining the matrix comparison with the FAHP scale then proceed the component weighting steps using the Fuzzy Analytical Hierarchy Process (FAHP) and proceed according to the steps in the literature review. With the same step continued weighting calculation of all sub criteria so as to result weighting Presented in table 13.

Table 13 weighting elements and component building

\begin{tabular}{|c|c|c|c|c|c|}
\hline Element & Weight & Component & Weight & Sub-Component & Weight \\
\hline \multirow{11}{*}{ Struktur } & \multirow{11}{*}{0,439} & Foundation & 0,222 & & \\
\hline & & Sloof & 0,154 & & \\
\hline & & Coloumn & 0,156 & & \\
\hline & & \multirow{2}{*}{ Beam } & \multirow{2}{*}{0,152} & Main Beam & 0,836 \\
\hline & & & & Secondary Beam & 0,164 \\
\hline & & \multirow{3}{*}{ Roof } & \multirow{3}{*}{0,124} & Rangka atap & 0,353 \\
\hline & & & & Penutup atap & 0,429 \\
\hline & & & & Lisplank & 0,218 \\
\hline & & \multirow{2}{*}{ Slabs } & \multirow{2}{*}{0,121} & Floor slabs & 0,478 \\
\hline & & & & Roof slabs & 0,304 \\
\hline & & Stairs & 0,071 & & \\
\hline \multirow{16}{*}{ Arsitektur } & \multirow{16}{*}{0,294} & \multirow{3}{*}{ Wall } & \multirow{3}{*}{0,214} & Brick layer & 0,362 \\
\hline & & & & Plester and finishng & 0,400 \\
\hline & & & & Paint wall & 0,238 \\
\hline & & \multirow{2}{*}{ Floor } & \multirow{2}{*}{0,235} & Ceramics Floor & 0,830 \\
\hline & & & & Rabat Floor & 0,170 \\
\hline & & \multirow{3}{*}{ Door } & \multirow{3}{*}{0,128} & Door Frames & 0,385 \\
\hline & & & & Leaf Door & 0,412 \\
\hline & & & & Accessories & 0,203 \\
\hline & & \multirow{3}{*}{ Window } & \multirow{3}{*}{0,135} & Window Frames & 0,326 \\
\hline & & & & Shutters & 0,389 \\
\hline & & & & Accessories & 0,285 \\
\hline & & \multirow{3}{*}{ Ceiling } & \multirow{3}{*}{0,164} & Frame & 0,324 \\
\hline & & & & Ceiling covers & 0,494 \\
\hline & & & & Cailing Paint & 0,182 \\
\hline & & \multirow{2}{*}{ Relling } & \multirow{2}{*}{0,124} & Stair Rellings & 0,534 \\
\hline & & & & Terrace Rellings & 0,466 \\
\hline \multirow{6}{*}{ Mekanikal } & \multirow{6}{*}{0,105} & \multirow{3}{*}{$\begin{array}{l}\text { Instalation of } \\
\text { Dirty Water }\end{array}$} & \multirow{3}{*}{0,301} & Pipe dirty water & 0,456 \\
\hline & & & & Toilet & 0,243 \\
\hline & & & & Saptictank & 0,301 \\
\hline & & \multirow{3}{*}{$\begin{array}{l}\text { Instalation of } \\
\text { Clean Water }\end{array}$} & \multirow{3}{*}{0,312} & Pipe clean water & 0,340 \\
\hline & & & & Water Faucet & 0,105 \\
\hline & & & & ground/roof tank & 0,119 \\
\hline
\end{tabular}




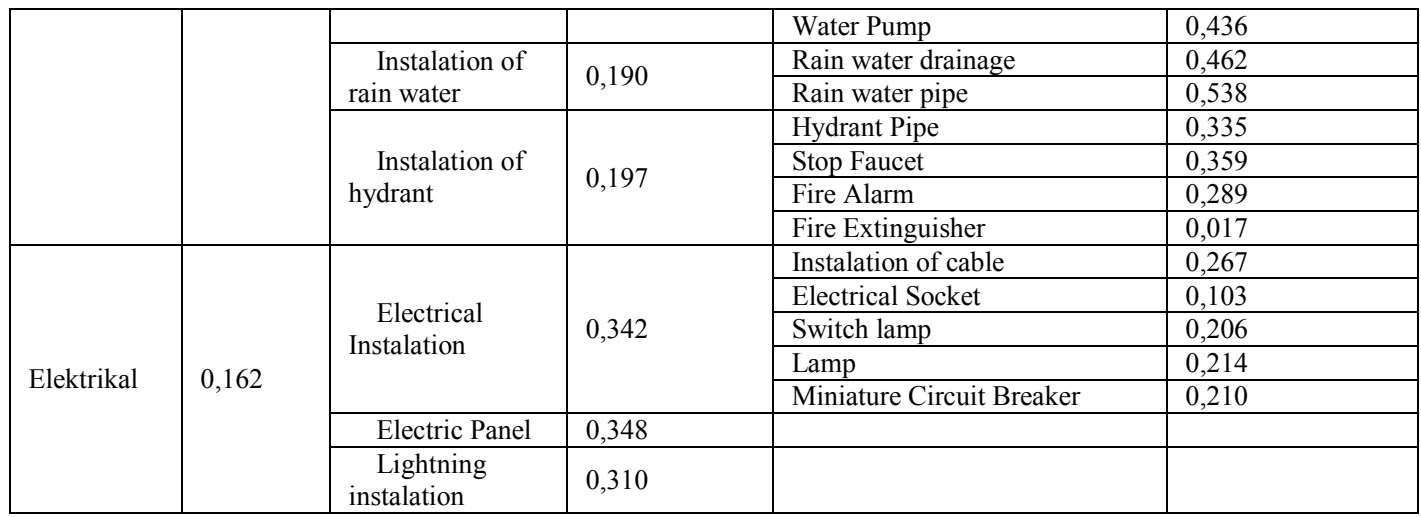

\section{Conclutions}

The results of the analysis show that by using the FAHP method, the weighting of building components from the assessment of the subjectivity of expert respondents can be calculated.

The result of this weighting can be used as a calculation factor of the value of the condition of the building, and can be applied to student dormitory buildings with typical design.

The analysis show that the weight assessment through FAHP analysis Element Structure has the highest weight that is 0.439 it means more important than the other criteria such as architecture $=0.294$, electrical $=0.105$, and mechanical $=0.162$.

\section{References}

1. Triwiyono, A. (2016), Department of Civil and Environmental Engineering Faculty of Engineering Gajah Mada University

2. Kuo.C.F.J., Lin. C.H., Hsu.M.W. , and Li.M.H. (2017). Energy and Buildings 139
3. Bhatt, Rajiv, dan Macwan J.E.M. (2015 Journal of Architectural Engineering 22 (1)

4. Santosa.P.A., Thesis, Gajah Mada University

5. Ministry of Public Works, 2008. PU Candy. No.24 / PRT / M Year 2008.

6. McKay, D.T., Rens, K.L., Stecker, J.H., dan Greimann, L.F., ASCE (1999).

7. Wai-Kiong Chong, M.ASCE; and Sui-Pheng Low , ASCE (2006).

8. Saaty, T.L., 2008, Int. J. Services Sciences, 2008.

9. Kabir, G. and Hansin, M., A., A., (IJFLS) (2011)

10. Saaty, T.L., and Vergas L.G., (2012) Models, Methods, Concepts \& Applications of the Analitic

11. Coulter, E.D., Coakley. J., Sessions.J. , (2006), Int. J. of Engineering from the Oregon State University Collage Forests.

12. Kengpol, A., Rontlaong,P., and Touminen, M., (2012), Proceedings of IEEE PICMET '12.

13. Chang,D.Y.,1996, European Journal of Operational Research 